\title{
Splenic hamartoma is a rare cause of abdominal pain: Case report and literature review
}

\author{
Tevfik Eker', Akın Fırat Kocaay', Yusuf Sevim², Atıl Çakmak
}

\begin{tabular}{|c|c|}
\hline ABSTRACT & $\begin{array}{l}\text { Hamartoma is a rare benign tumor of the spleen. It is often asymptomatic and diagnosed incidentally. In this study, } \\
\text { we report the case of a } 51 \text {-year-old female patient who was admitted to our department for intermittent epigastric } \\
\text { pain since the last } 6 \text { months and left upper quadrant fullness. She was diagnosed with splenic hamartoma histo- } \\
\text { pathologically after splenectomy. Although splenic hamartoma is very rare, it must be included in the differential } \\
\text { diagnosis of splenic mass-forming lesions. }\end{array}$ \\
\hline & Keywords: Splenic mass, hamartoma, splenectomy \\
\hline
\end{tabular}

\section{INTRODUCTION}

Splenic hamartoma (SH), which was first described in 1861 by Rokitansky, is a rare benign lesion of the spleen (1). Splenic hamartoma occurs equally in men and women (2). It is often asymptomatic and diagnosed incidentally $(2,3)$. Splenic hamartoma is generally a single lesion, with rare occurrence of multiple lesions. The size of $\mathrm{SH}$ ranges from a few millimeters to centimeters, with a median size of $5 \mathrm{~cm}$. A 20 $\mathrm{cm} \mathrm{SH}$ was reported in the literature (4). A minority of patients with large hamartomas have symptoms such as non-specific abdominal pain, thrombocytopenia, splenomegaly, fever, and night sweats $(3,4)$. In this study, we report the case of a 51-year-old female patient diagnosed with SH histopathologically.

\section{CASE PRESENTATION}

A 51-year-old female patient was admitted to our department for intermittent epigastric pain of 6 months' duration and left upper quadrant fullness. Physical examination was unremarkable, and blood tests revealed mild thrombocytopenia $\left(140 \times 10^{9} / \mathrm{L}\right)$. Abdominal ultrasonography (US) showed a $1-\mathrm{cm}$ mass in liver segment 7 and a splenic mass $5 \times 6 \mathrm{~cm}$ in size. Further investigation with abdominal and dynamic liver computed tomography (CT) scans were performed. Computed tomography analysis suspected a hemangioma for the liver mass and revealed intraparenchymal hypodense splenic lesion $(7 \mathrm{~cm}$ in size) with late phase enhancement after the administration of contrast material (Figure 1).

Splenectomy was performed for diagnosis and treatment. The patient was discharged from the hospital on the postoperative $8^{\text {th }}$ day without any complications. Pathological examination revealed round, wellcircumscribed, $8.5 \times 6 \times 6 \mathrm{~cm}$ in size, and unencapsulated bulging hamartoma containing fibrotic areas inside the tumor.

Cite this paper as: Eker T, Kocaay AF, Sevim Y, Çakmak A. Splenic hamartoma is a rare cause of abdominal pain: Case report and literature review. Turk J Surg 2017; 33: 294-295.

'Department of General Surgery, Ankara University School of Medicine, Ankara, Turkey

${ }^{2}$ Clinic of General Surgery, Kayseri Training and Research Hospital, Kayseri, Turkey

\section{Address for Correspondence} Tevfik Eker e-mail: tevfikeker@yahoo.com

Received: 25.12.2014 Accepted: 21.02.2015 Available Online Date: 14.07.2015

○Copyright 2017 by Turkish Surgical Association

\section{DISCUSSION}

Splenic hamartomas are rare benign lesions originating from the red or white pulp of the spleen. More than $80 \%$ of the cases are asymptomatic, and SHs are normally an incidental finding during imaging, surgery, or autopsy $(1,2)$. They can occur in any age group and equally in men and women (2). It tends to be larger in women probably because of female sex hormones (5). Approximately $20 \%$ of the patients are presented with non-specific symptoms. The main complaints of these patients are abdominal pain and digestion problems. In physical examination, spleen can be palpated below the costal margin or splenic mass can be palpated $(5,6)$. Splenic rupture caused by hamartomas has been reported only in a few patients in the literature (7).

Recently, Wang et al. (6) reviewed the features of the SH in US, colored Doppler US, CT, and magnetic resonance imaging (MRI) for radiological diagnosis. According to this study, SHs were generally detected as a hypoechoic solid mass in US, and they showed an inc-reased blood flow due to hypervascularity in Doppler US. On CT, SHs appeared as isodense or hypodense solid masses, and cystic and calcified areas in splenic lesions were found to be characteristic for the SHs. On MRI, it was isointense on T1-weighted images and was heterogeneously hyperintense on T2-weighted images (6).

The use of the fine-needle aspiration biopsy (FNAB) and cytological examination in splenic lesions are disputable. Although performing FNAB with US is helpful for diagnosis, FNAB by itself is not sufficient for definitive diagnosis $(2,8)$. 


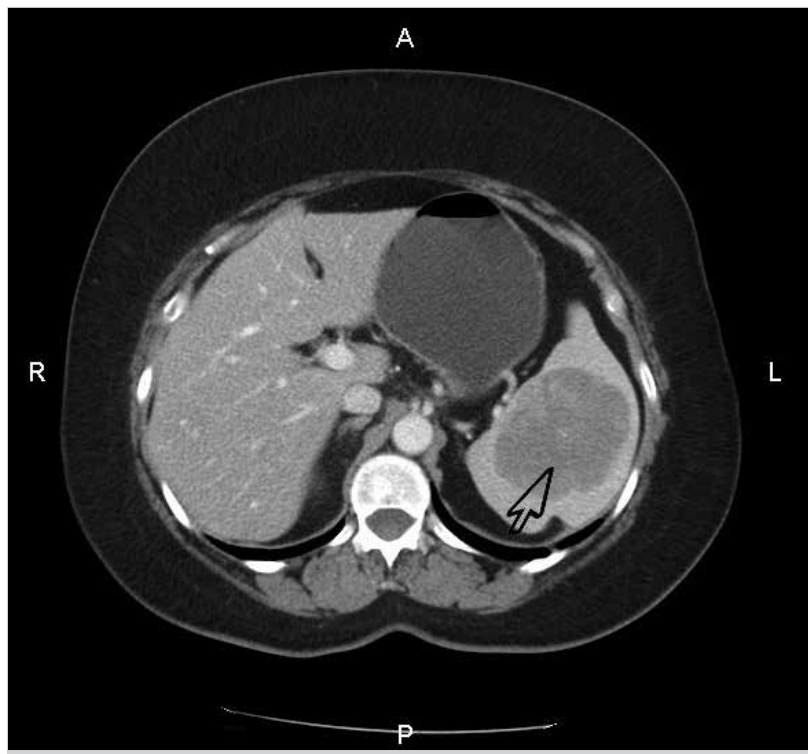

Figure 1. Contrast-enhanced computed tomography scan showing a solid mass ( $7 \mathrm{~cm}$ in diameter) in the center of the spleen

The open and laparoscopic procedures can be applied with lower mortality for diagnosis and treatment of SHs (9). Total or partial splenectomy can be performed safely for these patients. Although the use of partial splenectomy is not preferred in surgical practice today, it is significant for preserving the immunological functions of the spleen (10). The laparoscopic methods are preferred for partial splenectomy and smaller lesions, whereas total splenectomy or open surgical procedures are preferred for larger and multiple lesions (9).

In postoperative histopathological examinations, well-circumscribed single mass or multiple lesions are observed. Larger masses may cause pressure on normal splenic parenchyma. They may be divided into the red pulp type (disorganized splenic sinus), white pulp type (lymphoid tissue), mixed type (red and white pulp), and fibrous type (10). The structures of both pulps are found to be mixed in most SHs. The characteristic histological aspect is randomly located endothelial cells and vascular channels. Immunohistochemically, the lining cells of the vascular channels of the hamartoma are positive for the endothelial markers CD8, CD31, CD34, von Willebrand factor antigen, and vimentin (1).

Splenic hamartoma must be distinguished from splenic malignant lesions such as lymphangioma, hemangioblastoma, and angiosarcoma. In addition, in radiological differential diagnosis, inflammatory myofibroblast tumors; lymphoma; the rare splenic metastasis of malignant melanoma; and breast, lung and colorectal cancers should be considered $(5,6)$.

\section{CONCLUSION}

Splenic hamartoma is a benign vascular proliferative lesion. Because this tumor is very rare, it must be included in the differential diagnosis of splenic mass-forming lesions.

Informed Consent: Data was evaluated retrospectively after the required current treatment was completed, so the informed consent was not received.

Peer-review: Externally peer-reviewed.

Author Contributions: Concept - T.E.; Design - T.E.; Supervision - A.Ç.; Materials - A.Ç.; Data Collection and/or Processing - A.F.K.; Analysis and/or Interpretation - Y.S.; Literature Review - T.E.; Writer - T.E.; Critical Review - Y.S.

Conflict of Interest: No conflict of interest was declared by the authors.

Financial Disclosure: The authors declared that this study has received no financial support.

\section{REFERENCES}

1. Ali TZ, Beyer G, Taylor M, Volpe C, Papadimitriou JC. Splenic hamartoma: immunohistochemical and ultrastructural pro!le of two cases. Int J Surg Pathol 2005; 13: 103-111. [CrossRef]

2. Lee SH. Fine-needle aspiration cytology of splenic hamartoma. Diagn Cytopathol 2003; 28: 82-85. [CrossRef]

3. Hayes TC, Britton HA, Mewborne EB, Troyer DA, Saldivar VA, Ratner IA. Symptomatic splenic hamartoma: case report and literature review. Pediatrics 10.th Ed. 1998; 101.

4. Okada N, Ogura N, Kobayashi H, Terajima H, Wada M, Masai Y, et al. A case report of giant splenic hamartoma associated with thrombocytopenia. Jpn J Gastroenterol Surg 2006; 10: 15981603. [CrossRef]

5. Lee H, Maeda K. Hamartoma of the spleen. Arch Pathol Lab Med 2009; 133: 147-151.

6. Wang JH, Ma XL, Ren FY, Zuo CJ, Tian JM, Wang ZF, et al. Multi-modality imaging findings of splenic hamartoma: a report of nine cases and review of the literature. Abdom Imaging 2013; 38: 154-162. [CrossRef]

7. Yu RS, Zhang SZ, Hua JM. Imaging findings of splenic hamartoma. World J Gastroenterol 2004; 10: 2613-2615.

8. Conlon S, Royston D, Murphy P. Splenic hamartoma. Cytopathology 2007; 18: 200-202.

9. Uranues $S$, Alimoglu O. Laparoscopic surgery of the spleen. Surg Clin North Am 2005; 85: 75-90. [CrossRef]

10. Silverman ML, LiVolsi VA. Splenic hamartoma. Am J Clin Pathol 1978; 70: 224-229. 